\title{
Deglutitive Inhibition, Latency Between Swallow and Esophageal Contractions and Primary Esophageal Motor Disorders
}

\author{
Daniel Sifrim* and Jafar Jafari \\ Barts and The London School of Medicine and Dentistry, Queen Mary, University of London, London, UK
}

Swallowing induces an inhibitory wave that is followed by a contractile wave along the esophageal body. Deglutitive inhibition in the skeletal muscle of the esophagus is controlled in the brain stem whilst in the smooth muscle, an intrinsic peripheral control mechanism is critical. The latency between swallow and contractions is determined by the pattern of activation of the inhibitory and excitatory vagal pathways, the regional gradients of inhibitory and excitatory myenteric nerves, and the intrinsic properties of the smooth muscle. A wave of inhibition precedes a swallow-induced peristaltic contraction in the smooth muscle part of the human oesophagus involving both circular and longitudinal muscles in a peristaltic fashion. Deglutitive inhibition is necessary for drinking liquids which requires multiple rapid swallows (MRS). During MRS the esophageal body remains inhibited until the last of the series of swallows and then a peristaltic contraction wave follows. A normal response to MRS requires indemnity of both inhibitory and excitatory mechanisms and esophageal muscle. MRS has recently been used to assess deglutitive inhibition in patients with esophageal motor disorders. Examples with impairment of deglutitive inhibition are achalasia of the LES and diffuse esophageal spasm.

(J Neurogastroenterol Motil 2012;18:6-12)

Key Words

Deglutition disorders; Esophageal; Latency; Swallows

\section{Introduction}

The main function of the esophagus is the transport of food and liquid from the pharynx into the stomach. A rapidly progressing pharyngeal contraction transfers the bolus through a relaxed upper esophageal sphincter into the esophagus, and as the upper esophageal sphinctercloses, a progressive circular contraction begins in the upper esophagus and proceeds distally along the esophageal body to propel the bolus through a relaxed lower esophageal sphincter (LES). Therefore, in the esophagus, inhibition can play a role during the relaxation of both upper and lower esophageal sphincters, in the adequate organization of normal esophageal peristalsis and in the accommodation of the moving bolus.

Swallowing not only induces a contraction wave that progresses down the esophageal body but also triggers a wave of inhibition of the esophageal smooth muscle that precedes the arrival of the peristaltic contraction, resulting in relaxation of the lower esophageal sphincter and in preparation of the esophageal body to

Received: November 9, 2011 Revised: December 12, 2011 Accepted: December 20, 2011

(c) This is an Open Access article distributed under the terms of the Creative Commons Attribution Non-Commercial License (http://creativecommons. org/licenses/by-nc/3.0) which permits unrestricted non-commercial use, distribution, and reproduction in any medium, provided the original work is properly cited.

*Correspondence: Daniel Sifrim, MD, PhD

The Wingate Institute of Neurogastroenterology, 26 Ashfield Street, London E1 2AJ, UK

Financial support: None.

Tel: +44-0-20-7882-2631, Fax: +44-0-20-7375-2103, E-mail: d.sifrim@qmul.ac.uk

Conflicts of interest: None. 
receive the oncoming bolus with minimal distal resistance. ${ }^{1,2}$ Experiments in vitro and in vivo have shown a wave of muscle hyperpolarization that spreads down the esophageal body preceding the occurrence of peristaltic contractions. ${ }^{3-5}$ The initial hyperpolarization of the muscle lasts progressively longer in progressively more distal segments; hence it may play an important role during the latency period between swallowing and contraction, and as a consequence, in the normal propagation of primary peristalsis. ${ }^{3}$

In the striated muscle the peristaltic progression is coordinated by sequential excitation through vagal fibers programmed by a central control mechanism. ${ }^{6,7}$ The mechanism involved in the genesis of the aborally increasing latency gradient in the smooth muscle esophagus is more complex.

\section{Deglutitive Inhibition in Animal Studies}

Animal work in opossum and cat showed the presence of an intrinsic peripheral control mechanism in the smooth muscle portion of the esophagus, which can function independently from the central control. ${ }^{8-14}$ Activation of the intramural NANC inhibitory nerves induces a hyperpolarization of the cell membrane and the following contraction is thought to be a rebound phenomenon at the end of the inhibition (off-response); the latency gradient itself is built in the peripheral control system. ${ }^{8,15-22}$ Experiments using cat, baboon and rhesus monkey, ${ }^{23-25}$ and the recognized effect of atropine in human esophageal peristalsis ${ }^{26-28}$ do not deny the local mechanism in the myenteric plexus for distal inhibition via non-adrenergic non-cholinergic inhibitory neurons, but also suggest an important contribution of centrally controlled cholinergic excitatory neurons to the genesis of smooth muscle peristalsis.

Of interest, esophageal peristalsis can be induced in the smooth muscle esophagus in the presence of tetrodotoxin, which blocks all sodium channel-mediated action potentials in neurons. ${ }^{29-31}$ This can be evoked by electrical stimulation, esophageal distention or pharmacologic stimulation. It is believed that there is polarization of the muscle-to-muscle communication such that depolarization of one smooth muscle cell will result in electrotonic spread of current to adjacent muscle cells in an aboral direction. $^{32}$

Although an aborally increasing gradient in the duration of the initial inhibition is an attractive model to explain peristalsis, the calculated speed of peristalsis based on differences in the initial inhibition along the esophagus is on the order of $10 \mathrm{~cm} / \mathrm{sec},{ }^{33}$ which is much faster than peristalsis in vivo. Thus, there must be mechanisms other than the intrinsic latency gradient to explain peristalsis. Experiments in which simultaneous electrical and mechanical activity were recorded in both the proximal and distal opossum smooth muscle esophagus have helped clarify the discrepancy between the in vitro and in vivo observations. ${ }^{34}$ It was shown that an initial monophasic inhibitory potential occurs along the esophagus with either swallowing or balloon distention. The duration of the initial hyperpolarization was slightly longer distally than proximally, but this difference was insufficient to explain the marked delay of esophageal contraction in the distal versus the proximal smooth muscle esophagus. Rather, in the distal esophagus the initial monophasic inhibitory potential was followed by a second wave of hyperpolarization before the membrane potential rebounded into depolarization and initiation of spike potentials. It was suggested that this secondary hyperpolarization is likely due to reactivation of descending inhibitory neurons by distention or contraction of the more proximal esophagus in the course of peristalsis. This suggests that intramural descending inhibitory pathways are crucial in generating the peristaltic wave. Subsequent studies in the opossum have demonstrated that localized distention appears to directly activate intrinsic nitrergic inhibitory neurons that send long aboral projections. $^{35}$

In summary peristalsis in the esophageal smooth muscle is due to distally increasing duration of deglutitive inhibition followed by deglutitive excitation. Deglutitive inhibition in the skeletal muscle esophagus can be explained based on the inhibition of neuronal discharges in the brain stem. The pattern of activation of the inhibitory and excitatory vagal pathways, the regional gradients of inhibitory and excitatory myenteric nerves, and the intrinsic properties of the smooth muscle all determine the latency between swallow and contractions and the velocity of peristalsis. The esophageal peristaltic contractions themselves are a blend of noncholinergic and cholinergic components. As a consequence, cholinergic antagonists such as atropine increase the latency and decrease the amplitude of contraction in the proximal but not the distal parts of the esophagus. ${ }^{27}$ In contrast, antagonists of nitric oxide synthase reduce the latency mainly in the distal segments and lead to simultaneous contractions. ${ }^{36,37}$

\section{Demonstration of Deglutitive Inhibition in Human}

We provided for the first time, direct evidence that a wave of inhibition precedes a swallow-induced peristaltic contraction in the smooth muscle part of the human esophagus ${ }^{38}$ (Fig. 1). The inhibitory wave was visualized by the appearance, after degluti- 


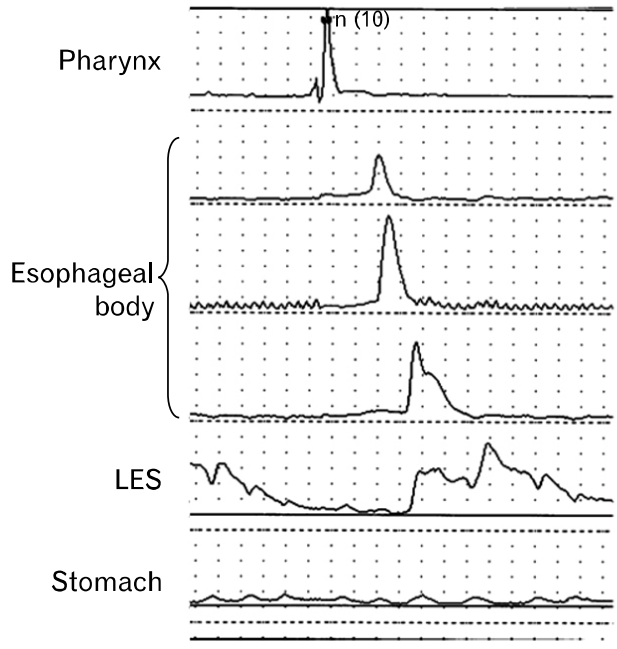

MRS

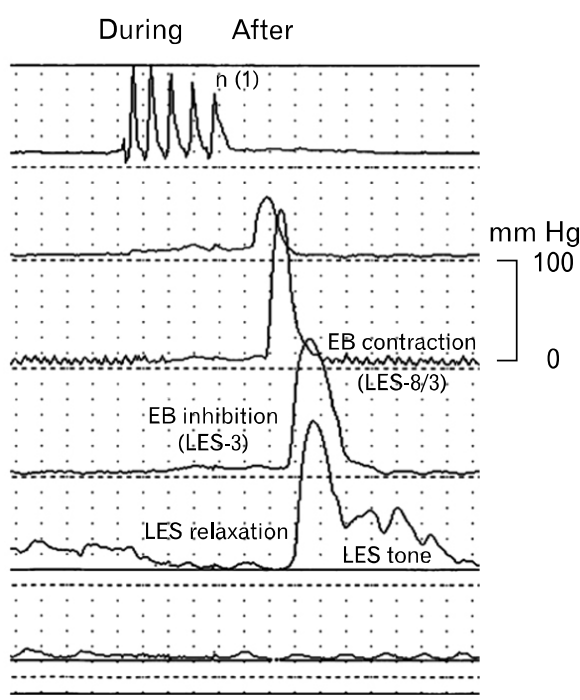

Figure 1. Multiple rapid swallowing (MRS) assessment. The analysis included variables assessed 'during' and 'after' MRS. Variables 'during' MRS were completeness of esophageal body (EB) inhibition and lower esophageal sphincter (LES) relaxation, whereas variables 'after' MRS were amplitude of contractions in the EB and LES tone immediately after the last MRS swallow. The example shows normal inhibition during MRS and normal response after MRS in a healthy asymptomatic volunteer (Adapted from Fornari et $\mathrm{al}^{64}$ ). tion, of a relaxation of the sustained contraction that was induced by insufflation of a balloon at different levels of the distal esophagus. This relaxation started simultaneously over the entire distal esophageal body, but lasted progressively longer in progressively more distal segments. ${ }^{39}$

Similar to circular muscles, deglutitive inhibition also occurs in the longitudinal muscles as demonstrated by the changes in distance of the radio-opaque markers implanted along the length of the esophagus in healthy volunteers (to measure longitudinal muscle contraction). ${ }^{40}$ A recent study using esophageal high frequency ultrasound and videofluoroscopy suggests that swallow-induced inhibition (distension) does not start simultaneously but rather traverses the esophagus in a peristaltic fashion. The authors propose that at any given instance during peristalsis a segment of the esophagus is contracted and similarly, a segment of the esophagus is inhibited and this segment traverses in front of the contraction segment. The peak distension (that represents the site of maximal inhibition) is located just distal to the site of the onset of esophageal contraction but there is a segment of the esophagus (involving circular and longitudinal muscle) of varying length, caudal to the site of peak distension that is also inhibited. $^{41}$

\section{Deglutitive Inhibition During Multiple Rapid Swallowing}

Deglutitive inhibition follows each individual swallow. This phenomenon is essential for drinking of fluids at a rate faster than one swallow every 10 seconds. This is because the esophageal contraction in response to a single swallow lasts 8 to 10 seconds, and this will obstruct the bolus of a second swallow taken less than 8 second afterward. However, during the usual drinking of water, swallows may be accomplished every 1 to 2 seconds. This is made possible by the phenomenon of deglutitive inhibition in which a swallow abruptly inhibits any ongoing contraction in the esophagus. When multiple swallows are taken in rapid succession, the esophageal body remains inhibited until the last of the series of swallow, after which there is a fully conducted peristaltic contraction wave. This phenomenon was initially described by Hightower $^{42}$ and later confirmed by many other investigators. $^{26,43-49}$

During rapid swallows, larynx remains elevated and upper esophageal sphincter remains open, pharynx may or may not contract, esophageal and LES remain relaxed. Esophagus becomes a simple conduit for the transfer of fluid pumped by the oropharynx into the stomach. If person swallows for the second time soon after the completion of first peristaltic contraction, amplitude of contraction related to the second swallow is lower than the first swallow, a phenomenon related to the refractoriness of esophageal muscle. $^{47,49}$

Deglutitive inhibition during multiple rapid swallows reflects both a peripheral inhibitory discharge to the esophageal smooth muscle and a central inhibitory phenomenon that occurs with each swallow. ${ }^{46}$ 


\section{Deglutitive Inhibition and Primary Esopha- geal Motor Disorders}

Any condition in the gastrointestinal tract which impairs neural inhibitory activity will probably result in a discoordinated motor behavior. In the esophagus, the classical example of degenerative loss of neurons and impairment of inhibitory activity is achalasia of the LES.

In 1970 Christensen suggested that a system of local inhibitory innervation had to be studied to understand the pathogenesis of diffuse esophageal spasm and achalasia. ${ }^{15}$

Evidence of inhibitory dysfunction associated with abnormal peristalsis and/or incomplete LES relaxation has been found both in animal experiments ${ }^{50-52}$ and in patients with achalasia. ${ }^{53-58}$ Since then many investigators proposed that the spectrum of primary esophageal motility disorders may be due to different degrees of inhibitory dysfunction. ${ }^{15,48,59-61}$

Important evidence of impaired deglutitive inhibition in the esophageal body of patients with diffuse esophageal spasm and nonspecific esophageal motility disorders, has come from studies using paired swallows ${ }^{54,62}$ (Fig. 2). Two swallows taken at 5-second interval evoked a single contraction sequence in normal subjects but induced one contraction sequence after each swallow in patients with simultaneous contractions, denoting a weaker inhibitory interaction between swallows in patients with primary esophageal motility disorders. ${ }^{62}$

We used our technique to visualize deglutitive inhibition (by the appearance, after deglutition, of a relaxation of the sustained contraction that was induced by insufflation of a balloon in the distal esophagus) in patients with achalasia, diffuse esophageal spasm and intermediate forms. An inverse relationship was found between the degree of inhibition and the propagation velocity of deglutitive esophageal contractions: the less inhibition, the faster the propagation velocity, and in the extreme case of zero-inhibition the presence of simultaneous contractions. Our results, therefore, provided evidence in man for the hypothesis that the spectrum of primary esophageal motility disorders is an expression of a progressively failing inhibition. ${ }^{39}$

More recently, multiple rapid swallowing (MRS) was used to assess deglutitive inhibition in patients with esophageal motor disorders. MRS provokes not only absence of contractions in the smooth muscle portion of the esophagus and complete relaxation of the LES. The last swallow of the MRS series is followed by a powerful peristaltic sequence in the esophageal body together with a post relaxation contraction in the LES (Fig. 3). A normal response to multiple rapid swallowing requires on the one hand
A

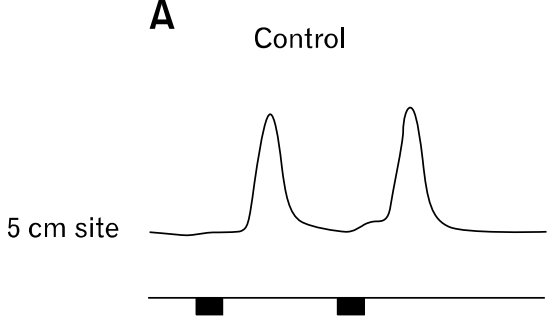

ISI $5 \mathrm{sec}$
B

Initial inhibition

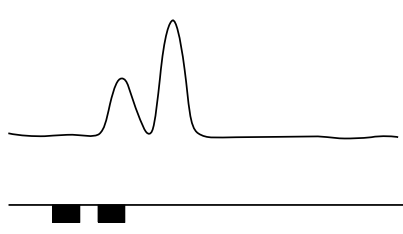

ISI $1 \mathrm{sec}$
C

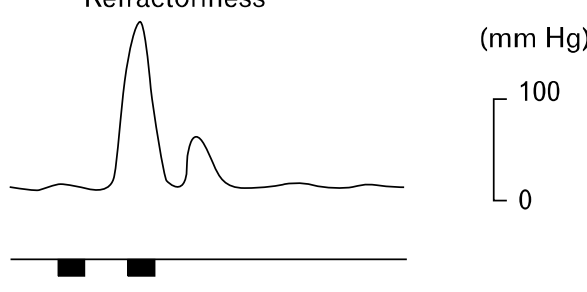

ISI $2 \mathrm{sec}$

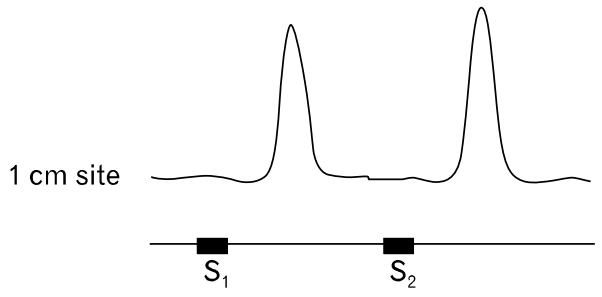

ISI $7 \mathrm{sec}$

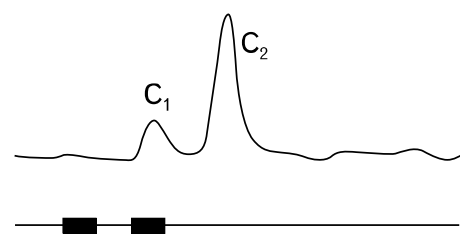

ISI $2 \mathrm{sec}$

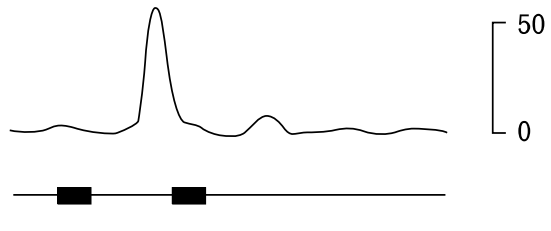

ISI $4 \mathrm{sec}$

Figure 2. Esophageal contractions to pairs of vagal stimulus trains at different intervals (ISI) at the 5 and $1 \mathrm{~cm}$ sites above the lower esophageal sphincter. (A) Control esophageal contractions. Note that the 2 contractions were equal when ISI was 5 seconds at the $5 \mathrm{~cm}$ site and 7 seconds at the $1 \mathrm{~cm}$ site. (B) Esophageal contractions showing initial inhibition. Note that the first contraction was inhibited by the second stimulus at an ISI of 1 second at the $5 \mathrm{~cm}$ site and 2 seconds at the $1 \mathrm{~cm}$ site. (C) Esophageal contractions showing refractoriness. Note that the first contraction inhibited the second contraction at an ISI of 2 seconds at the $5 \mathrm{~cm}$ site and at an ISI of 4 seconds at the $1 \mathrm{~cm}$ site. Stimulus parameters: $5 \mathrm{~mA}, 0.5 \mathrm{~ms}, 10 \mathrm{~Hz}$ and 1 second train. $\mathrm{S} 1=$ first stimulus train; $\mathrm{S} 2=$ second stimulus train; $\mathrm{C} 1=$ first contraction; $\mathrm{C} 2=$ second contraction. 
A

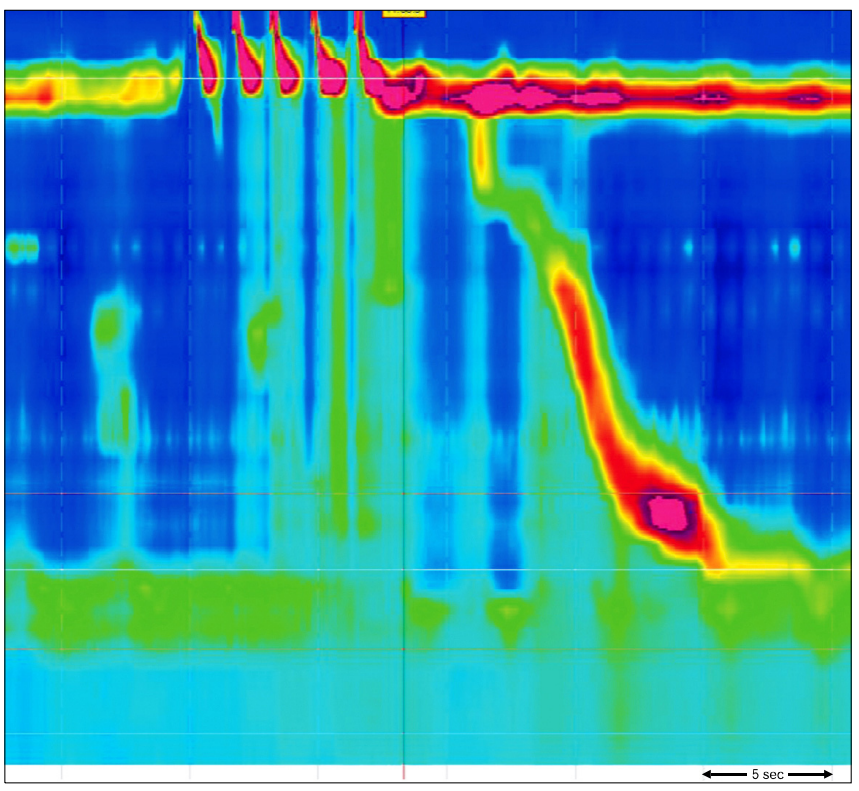

B

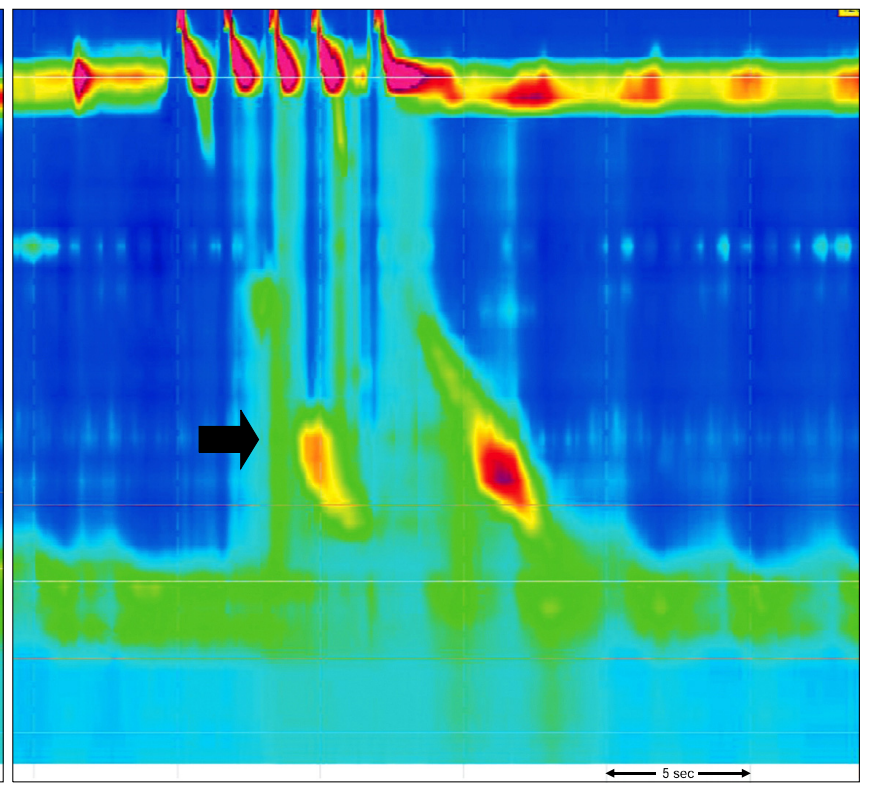

Figure 3. Multiple rapid swallowing. Normal inhibition in esophageal body (A) and a patient with dysphagia showing incomplete inhibition in esophageal body (B). Note contractions in the distal oesophagus in spite of repetitive swallowing (arrow).

indemnity of inhibitory and excitatory mechanisms and on the other hand, esophageal muscle indemnity able to respond to a strong stimulation at the end of the MRS. As expected, multiple rapid swallowing induced an abnormal response in patients with achalasia. ${ }^{63}$ In contrast, symptomatic patients (dysphagia, chest pain or heartburn) with normal standard manometry showed preserved inhibition during MRS with a more significant abnormality in the post-MRS after contractions. ${ }^{64}$

The impact of MRS in esophageal inhibition and contractility can be better assessed using high resolution manometry. The degree of impairment in deglutitive inhibition and its impact on swallow to contractions latencies in patients with dysphagia is currently under investigation using HRM.

\section{Conclusion}

From the previous discussion it is clear that inhibition plays an important role in normal esophageal motility. The propagation of peristaltic contractions in the smooth muscle portion of the esophagus is controlled by the action of inhibitory and excitatory nerves. This inhibition is essential for the peristaltic nature of the contractions and it may contribute to a slower propagation in case of a big intraluminal bolus. The deglutitive inhibition also precludes the occurrence of very rapidly propagated or simultaneous contractions.

\section{References}

1. Vantrappen G. Cellular physiology and clinical studies of gastrointestinal smooth muscle. New York: Elsevier Science Publishers 1987:287-309.

2. Mittal RK, Ren J, McCallum RW, Shaffer HA, Sluss J. Modulation of feline esophageal contractions by bolus volume and outflow obstruction. Am J Physiol 1990;258(1 Pt 1):G208-G215.

3. Goyal RK, Gidda JS. Relation between electrical and mechanical activity in esophageal smooth muscle. Am J Physiol 1981;240:G305G311.

4. Paterson WG. Electrical correlates of peristaltic and nonperistaltic contractions in the opossum smooth muscle esophagus. Gastroenterology 1989;97:665-675.

5. Sugarbaker D, Rattan S, Goyal RK. Mechanical and electrical activity of esophageal smooth muscle during peristalsis. Am J Physiol 1984;246(2 Pt 1):G145-G150.

6. Hwang K. Mechanism of transportation of the content of the esophagus. J Appl Physiol 1954;6:781-796.

7. Roman C. [Nervous control of peristalsis in the esophagus.] J Physiol (Paris) 1966;58:79-108. [French]

8. Christensen J, Lund GF. Esophageal responses to distension and electrical stimulation. J Clin Invest 1969;48:408-419.

9. Goyal RK, Rattan S. Nature of the vagal inhibitory innervation to the lower esophageal sphincter. J Clin Invest 1975;55:1119-1126.

10. Mukhopadhyay AK, Weisbrodt NW. Neural organization of esophageal peristalsis: role of the vagus nerve. Gastroenterology 1975;68: 
444-447.

11. Dodds WJ, Christensen J, Dent J, Wood JD, Arndorfer RC. Esophageal contractions induced by vagal stimulation in the opossum. Am J Physiol 1978;235:E392-E401.

12. Dodds WJ, Stef JJ, Stewart ET, Hogan WJ, Arndorfer RC, Cohen EB. Response of feline esophagus to cervical vagal stimulation. Am J Physiol 1978;235:E63-E73.

13. Reynolds RP, el-Sharkawy TY, Diamant NE. Oesophageal peristalsis in the cat: the role of central innervation assessed by transient vagal blockade. Can J Physiol Pharmacol 1985;63:122-130.

14. Blank EL, Greenwood B, Dodds WJ. Cholinergic control of smooth muscle peristalsis in the cat esophagus. Am J Physiol 1989;257(4 Pt 1):G517-G523.

15. Christensen J. Patterns and origin of some esophageal responses to stretch and electrical stimulation. Gastroenterology 1970;59:909916.

16. Diamant NE. Electrical activity of the cat smooth muscle esophagus: a study of hyperpolarizing responses. In: Daniel EE, ed. Proceedings of the 4th International Symposium on Gastrointestinal Motility. Vancouver: Mitchel Press 1974:593-605.

17. Diamant NE, Chan WW. The electrical off response of cat circular esophageal smooth muscle: the effect of stimulus frequency on its timing. In: Vantrappen G, ed. Proceedings of the 5th International Symposium on Gastrointestinal Motility. Leuven: Typoff-Press 1975: 158-163.

18. Chan WW, Diamant NE. Electrical off response of cat esophageal smooth muscle: an analog simulation. Am J Physiol 1976;230:233238.

19. Cobb BW, Gidda JS, Goyal RK. Mechanism of esophageal peristalsis: latency gradients and slow electrical response due to vagal and intramural stimulation [abstract]. Gastroenterology 1980;78:1150.

20. Daniel EE, Helmy-Elkholy A, Jager LP, Kannan MS. Neither a purine nor VIP is the mediator of inhibitory nerves of opossum oesophageal smooth muscle. J Physiol 1983;336:243-260.

21. Crist J, Gidda JS, Goyal RK. Intramural mechanisms of esophageal peristalsis: roles of cholinergic and non cholinergic nerves. Proc Natl Acad Sci USA 1984;81:3595-3599.

22. Kannan MS, Jager LP, Daniel EE. Electrical properties of smooth muscle cell membrane of opossum esophagus. Am J Physiol 1985; 248:G342-G346.

23. Roman C, Tieffenbach L. [Recording the unit activity motor fibers innervating the baboon esophagus.] J Physiol (Paris) 1972;64:479506. [French]

24. Janssens J, Vantrappen G, Agg Ho, De Wever I, Hellemans J. Peristalsis in the smooth muscle esophagus after transection and bolus deviation. In: Vantrappen G, ed. Proceedings of the 5th International Symposium on Gastrointestinal Motility. Leuven: TypoffPress 1975:209-212.

25. Gidda JS, Goyal RK. Swallow-evoked action potentials in vagal preganglionic efferents. J Neurophysiol 1984;52:1169-1180.

26. Hellemans J, Vantrappen G, Janssens J. Electromyography of the esophagus. In: Vantrappen G, Hellemans J, eds. Diseases of the esophagus. New York: Springer Verlag 1974:270-285.

27. Dodds WJ, Dent J, Hogan WJ, Arndorfer RC. Effect of atropine on esophageal motor function in humans. Am J Physiol 1981;240: G290-G296.
28. Paterson WG, Hynna-Liepert T, Seluky M. Comparison of primary and secondary peristalsis in humans: effect of atropine. Am J Physiol 1991;260(1 Pt 1):G52-G57.

29. Sarna SK, Daniel EE, Waterfall WE. Myogenic and neural control systems for esophageal motility. Gastroenterology 1977;73:13451352.

30. Helm JF, Bro SL, Dodds WJ, Sarna SK, Hoffman RG. Myogenic mechanism for peristalsis in opossum smooth muscle esophagus. Am J Physiol 1992;263(6 Pt 1):G953-G959.

31. Preiksaitis HG, Diamant NE. Myogenic mechanism for peristalsis in the cat esophagus. Am J Physiol 1999;277(2 Pt 1):G306-G313.

32. Daniel EE, Bardakjian BL, Huizinga JD, Diamant NE. Relaxation oscillators and core conductor models are needed for understanding of GI electrical activities. Am J Physiol 1994;266(3 Pt 1):G339G349.

33. Serio R, Daniel EE. Electrophysiological analysis of responses to intrinsic nerves in circular muscle of opossum esophageal muscle. Am J Physiol 1988;254(1 Pt 1):G107-G116.

34. Rattan S, Gidda J, Goyal RK. Membrane potential and mechanical responses of the opossum esophagus to vagal stimulation and swallowing. Gastroenterology 1983;85:922-928.

35. Paterson WG, Indrakrishnan B. Descending peristaltic reflex in the opossum esophagus. Am J Physiol 1995;269(2 Pt 1):G219-G224.

36. Conklin JL. Nitric oxide: a mediator of esophageal motor function. J Lab Clin Med 1998;131:10-20.

37. Murray JA, Ledlow A, Launspach J, Evans D, Loveday M, Conklin $\mathrm{JL}$. The effects of recombinant human hemoglobin on esophageal motor functions in humans. Gastroenterology 1995;109:1241-1248.

38. Sifrim D, Janssens J, Vantrappen G. A wave of inhibition precedes primary peristaltic contractions in the human esophagus. Gastroenterology 1992;103:876-882.

39. Sifrim DA, Janssens J, Vantrappen G. Failing deglutitive inhibition in primary esophageal motility disorders. Gastroenterology 1994; 106:875-882.

40. Shi G PJ, Pandolfino JE, Zhang Q, Hirano I, Joehl RJ, Kahrilas PJ. Deglutitive inhibition affects both esophageal peristaltic amplitude and shortening. Am J Physiol Gastrointest Liver Physiol 2003;284: G575-G582.

41. Abrahao L, Bahargava V, Babaei A, Mittal RK. Swallow induces a peristaltic wave of distension that marches in front of the peristaltic wave of contraction. Neurogastroenterol Motil 2011;23:201-207, e110.

42. Hightower NC Jr. Esophageal motility in health and disease. Dis Chest 1955;28:150-169.

43. Doty RW. Neural organization of deglutition. In: Code CF, ed. Handbook of physiology, sect 6: alimentary canal. vol A. Washington: American Physiological Society 1968:1861-1902.

44. Vantrappen G, Hellemans J, Pelemans W, Janssens J. Electromyographic and manometric studies of the deglutitive inhibition in the esophagus [abstract]. Rendic R Gastroenterol 1971;3:139.

45. Janssens J. Studies on the deglutitive inhibition of esophageal peristalsis. Leuven: Acco 1978:169-188.

46. Ask P, Tibbling L. Effect of time interval between swallows on esophageal peristalsis. Am J Physiol 1980;238:G485-G490.

47. Meyer GW, Gerhardt DC, Castell DO. Human esophageal response to rapid swallowing: muscle refractory period or neural in- 
hibition? Am J Physiol 1981;241:G129-G136.

48. Gidda JS, Goyal RK. Regional gradient of initial inhibition and refractoriness in esophageal smooth muscle. Gastroenterology 1985;89: 843-851.

49. Vanek AW, Diamant NE. Responses of the human esophagus to paired swallows. Gastroenterology 1987;92:643-650.

50. Gidda JS, Buyniski JP. Swallow-evoked peristalsis in opossum esophagus: role of cholinergic mechanisms. Am J Physiol 1986; 251(6 Pt 1):G779-G785.

51. Helm JF, Layman RD, Eckert MD. Effect of chronic administration of Nw-Nitro-L-Arginine (LNNA) on the opossum esophagus and lower esophageal sphincter (LES) resembles achalasia. Gastroenterology 1992;103:1375.

52. Yamato S, Spechler SJ, Goyal RK. Role of nitric oxide in esophageal peristalsis in the opossum. Gastroenterology 1992;103:197-204.

53. Dodds WJ, Dent J, Hogan WJ, Parel GK, Toouli J, Arndorfer RC. Paradoxical lower esophageal sphincter contraction induced by cholecystokinin-octapeptide in patients with achalasia. Gastroenterology 1981;80:327-333.

54. Bortolotti M, Labò G, Bragaglia RB, Mattioli S, Possati L. Electromyographic study in diffuse esophageal spasm and achalasia. In: Wienbeck M, ed. Motility of the digestive tract. New York: Raven Press 1982:319-327.

55. Aggestrup S, Uddman R, Sundler F, et al. Lack of vasoactive intestinal polipeptide nerves in esophageal achalasia. Gastroenterology 1983;84(5 Pt 1):924-927.

56. Holloway RH, Wyman JB, Dent J. Failure of transient lower esoph- ageal sphincter relaxation in response to gastric distension in patients with achalasia. Gut 1989;30:762-767.

57. Holloway RH, Dodds WJ, Helm J, Hogan WJ, Dent J, Arndorfer $\mathrm{RC}$. Integrity of cholinergic innervation in the lower esophageal sphincter in achalasia. Gastroenterology 1986;90:924-929.

58. Tøttrup A, Forman A, Funch-Jensen P, Raundahl U, Andersson KE. Effects of postganglionic nerve stimulation in oesophageal achalasia: an in vitro study. Gut 1990;31:17-20.

59. DiMarino AJ Jr. Characteristics of lower esophageal sphincter function in symptomatic diffuse esophageal spasm. Gastroenterology 1974; 66:1-6.

60. Gidda JS, Goyal RK. Influence of succesive vagal stimulations on contractions in esophageal smooth muscle of opossum. J Clin Invest 1982;71:1095-1103.

61. Ouyang A, Reynolds JC, Cohen S. Spike-associated and spike-independent esophageal contractions in patients with symptomatic diffuse esophageal spasm. Gastroenterology 1983;84(5 Pt 1):907-913.

62. Behar J, Biancani P. Pathogenesis of simultaneous esophageal contractions in patients with motility disorders. Gastroenterology 1993; 105:111-118.

63. Savojardo D, Mangano M, Cantù P, Penagini R. Multiple rapid swallowing in idiopathic achalasia: evidence for patients' heterogeneity. Neurogastroenterol Motil 2007;19:263-269.

64. Fornari F, Bravi I, Penagini R, Tack J, Sifrim D. Multiple rapid swallowing: a complementary test during standard oesophageal manometry. Neurogastroenterol Motil 2009;21:718-e41. 